\title{
Kinetic and Isotherm Studies of Removal of Metanil Yellow Dye on Mesoporous Aluminophosphate Molecular Sieves
}

\author{
KUMARASAMY MUTHURAJA and CHELLAPANDIAN KANNAN* \\ Department of Chemistry, Manonmaniam Sundaranar University, Tirunelveli-627012, \\ Tamilnadu, India
}

chellapandiankannan@gmail.com

Received 28 January 2013 / Accepted 15 February 2013

\begin{abstract}
The removal of metanil yellow dye was studied through adsorption on meosporous aluminophosphate molecular sieves at different experimental conditions like contact time, $\mathrm{pH}$, dye concentration and adsorbent dosage. The experimental values were adopted to adsorption kinetic and adsorption isotherm equations for understanding the rate and mechanism of adsorption process. The adsorption process was well fitted with pseudo first second kinetics and Langmuir adsorption isotherm. The maximum adsorption capacity of metanil yellow on adsorbent was $75 \mathrm{mg} / \mathrm{g}$. This study concludes that the mesoporous aluminophosphate material is a good material for removal of metanil yellow dye.
\end{abstract}

Keywords: Kinetics, Isothermal studies, Removal of Metanil yellow, Mesoporous aluminophosphate

\section{Introduction}

Plants and soil are highly polluted by dye effluent released from dyeing and dye manufacturing industries. More than $12 \%$ of dyes are discharged from industries like textile, leather tanning and paper production. Physicochemical methods were introduced to solve the dye pollution problem like photocatalytic degradation, adsorption and biodegradation ${ }^{1-3}$. Among these techniques for dyes removal from aqueous solution, adsorption has been proved to be an effective process ${ }^{4}$. In previous investigations, many adsorbents have been investigated for the removal of dyes from aqueous solution, including silica and alumina ${ }^{5}$.

In the present article, we have studied the removal of hazardous anionic dye, metanil yellow (MY) through adsorption on mesoporous aluminophosphate $\left(\mathrm{AlPO}_{4}\right)$ molecular sieves at different experimental condition for measuring the maximum removal of MY. The adsorption rate and adsorption isotherms were analyzed by using pseudo second order kinetic equation and adsorption isotherm equations (Langmuir and Freundlich) respectively.

\section{Experimental}

The synthesis and characterization of mesoporous aluminophosphate molecular sieves was given in our previous research article ${ }^{6}$. The anionic dye metanil yellow (MY) was purchased from Loba Chemie Pvt. Ltd. It was used as an adsorbate for the kinetic and adsorption isotherm studies of removal by using mesoporous aluminophosphate from aqueous solution. A double beam UV/ VIS spectrophotometer (Perkin Elmer, Lambda 25) was used to determine the concentration of dye samples. The $\mathrm{pH}$ of the solutions was measured by $\mathrm{pH}$ meter, Elico-model.

$\dagger$ Presented to the National Conference on Chemistry Solutions at SRM University, India 


\section{Preparation of stock solution}

Stock solution (1000 mg/L) of MY dye was prepared by dissolving in double-distilled water. Experimental solutions of the desired concentrations were obtained by successive dilutions with distilled water.

\section{Adsorption experiment}

The mesoporous $\mathrm{AlPO}_{4}$ was activated by heating in an electric Bunsen at $773 \mathrm{~K}$ for 4 hours to remove the physically adsorbed species present in the pores and the surface. Then the $0.5 \mathrm{~g}$ of mesoporous $\mathrm{AlPO}_{4}$ was added with $50 \mathrm{~mL}$ of MY dye solution. The solution was agitated (Kemi agitator) at $150 \mathrm{rpm}$. The solution concentration was measured by spectrophotometrically. The effect of contact time was studied up to adsorption equilibrium. The effect of $\mathrm{pH}$ was studied in the $\mathrm{pH}$ range from 2 to 11 . The adsorption of MY by mesoporous $\mathrm{AlPO}_{4}$ was studied in the concentration range of $100-500 \mathrm{mg} / \mathrm{L}$. adsorbent dosage effect was studied in the range of $0.5-2.5 \mathrm{~g}$. The adsorption capacity (mg dye/g adsorbent) of mesoporous $\mathrm{AlPO}_{4}$ was calculated by using the following equation,

$$
\mathrm{q}=\left(\mathrm{C}_{0}-\mathrm{C}_{\mathrm{e}}\right) \mathrm{V} / \mathrm{W}
$$

The dye removal percentage $(\%)$ was calculated by using the following equation:

$$
\text { Dye removal in percentage }=\left(\mathrm{C}_{0}-\mathrm{C}_{\mathrm{e}}\right) \mathrm{X} 100 / \mathrm{C}_{0}
$$

Where; $q$ is the amount of MY adsorbed on mesoporous $\mathrm{AlPO}_{4}\left(\mathrm{mg} \mathrm{g}^{-1}\right), \mathrm{C}_{0}$ and $\mathrm{C}_{\mathrm{e}}$ are the initial and final MY concentrations in solution $\left(\mathrm{mg} \mathrm{L}^{-1}\right)$, respectively. $\mathrm{V}$ is the volume of dye solution (L) and $\mathrm{W}$ is the mesoporous $\mathrm{AlPO}_{4}$ weight $(\mathrm{g})$.

\section{Results and Discussion}

\section{Effect of contact time}

The effect of contact time was carried out at room temperature for the adsorption of MY on mesoporous $\mathrm{AlPO}_{4}$ upto the equilibrium attained (Figure 1). The rapid adsorption was observed at 20 minutes. Further increase of contact time not much influence the adsorption of dyes over $\mathrm{AlPO}_{4}$. This is due to the saturation of active sites present in the mesoporous $\mathrm{AlPO}_{4}$.

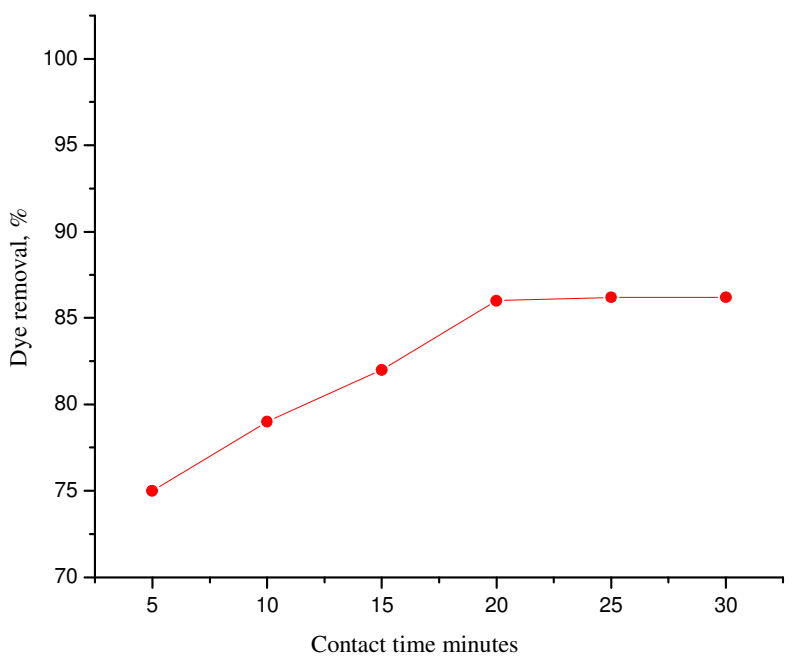

Figure 1. Contact time effect of removal of $\mathrm{MY}$ on mesoporous aluminophosphate molecular sieves 


\section{Effect of $p H$}

The removal of metanil yellow was highly influenced by the $\mathrm{pH}$ factor. The effect of $\mathrm{pH}$ was studied in the $\mathrm{pH}$ range from 2 to 11 using the $100 \mathrm{mg} / \mathrm{L}$ dye solutions is shown in Figure 2. The adsorptioin percentage decreased with increase of $\mathrm{pH}$ and maximum at $\mathrm{pH}-2$. The increasing of $\mathrm{H}^{+}$ions at low $\mathrm{pH}$ attracted the negatively charged dye molecules. When $\mathrm{pH}$ increases above 7, the surface of the mesoporous aluminophosphate molecular sieves was occupied negatively charged $\mathrm{OH}^{-}$ions and the repulsive force produced with anionic dye (MY) and hence the adsorption of MY decreases.

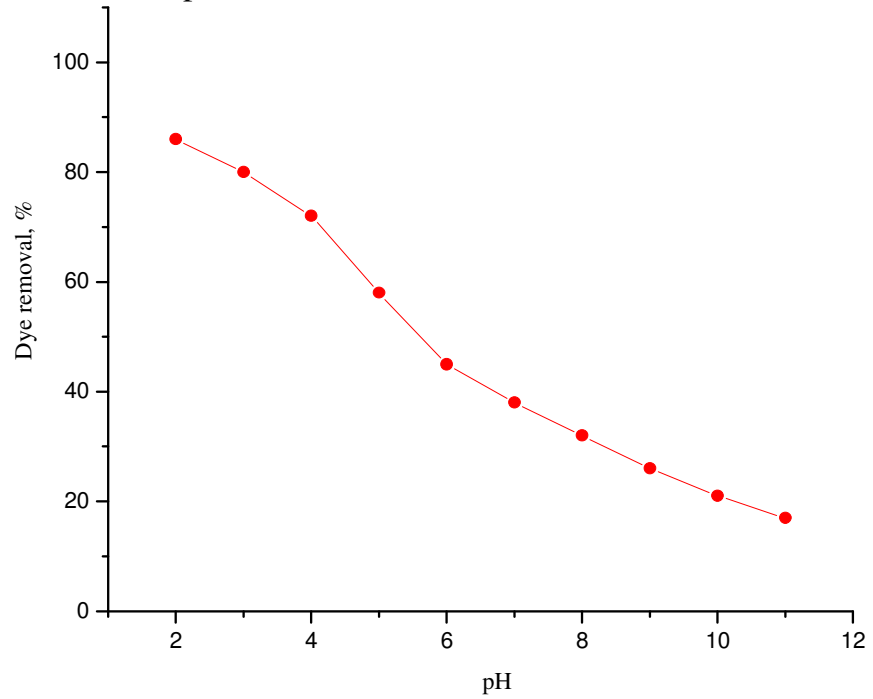

Figure 2. pH effect of removal of MY on mesoporous aluminophosphate molecular sieves

\section{Effect of dye concentration}

MY removal on mesoporous $\mathrm{AlPO}_{4}$ was studied between dye concentration ranges $100 \mathrm{mg} / \mathrm{L}$ $-500 \mathrm{mg} / \mathrm{L}$ at room temperature is shown in Figure 3. The adsorption percentage of mesoporous $\mathrm{AlPO}_{4}$ was found to be maximum at $100 \mathrm{mg} / \mathrm{L}$ and further increased of concentration decreased the adsorption of MY on the adsorbent. The initial concentration provides an important driving force to overcome all mass transfer resistance of the dye between the aqueous and solid phases.

\section{Effect of adsorbent dosage}

The effect of adsorbent dosage (500-2500 mg) on adsorption of MY was studied (Figure 4). The percentage removal of the MY was increased with increase of adsorbent dosage. Since the increased of adsorbent dosage increased the surface area and active sites. Hence, adsorption increased with increase of mesoporous $\mathrm{AlPO}_{4}$ dosage.

\section{Adsorption kinetic study}

From the contact time studies, the adsorption kinetics of MY on mesoporous $\mathrm{AlPO}_{4}$ was studied as a model study for find out the rate constant of the adsorption process. The experimental values were introduced in the pseudo second order kinetics equation for calculating the rate constant. The equation for adsorption kinetics is;

$$
\mathrm{t} / \mathrm{Q}_{\mathrm{t}}=1 / \mathrm{kQ}_{\mathrm{e}}{ }_{\mathrm{e}}+1 / \mathrm{Q}_{\mathrm{e}} \mathrm{t}
$$




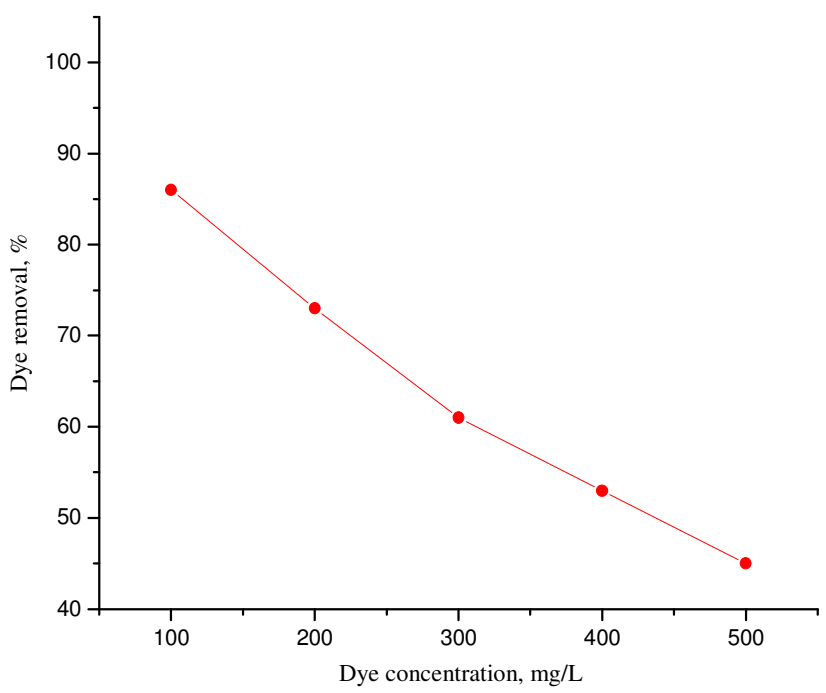

Figure 3. Dye concentration effect of removal of MY on mesoporous aluminophosphate molecular sieves

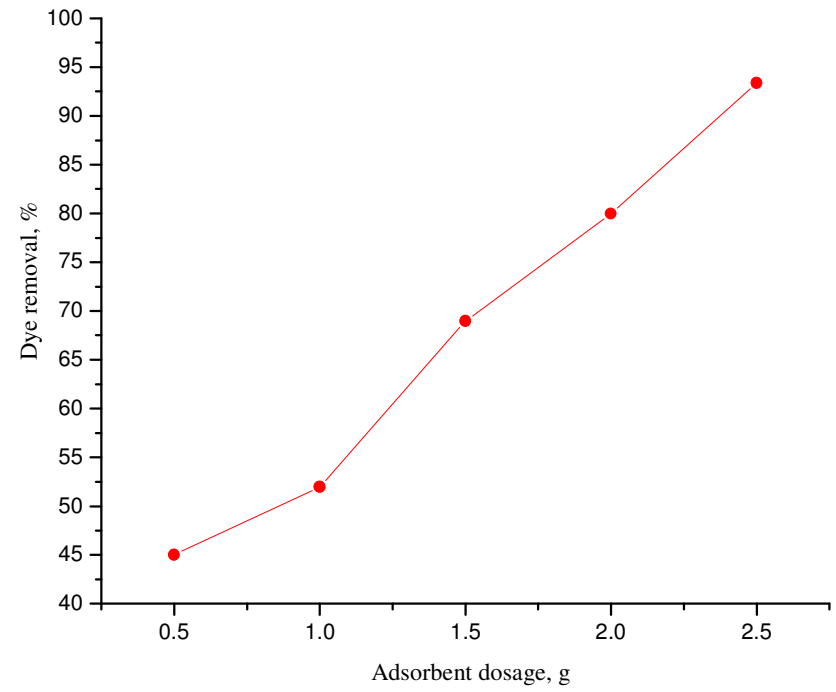

Figure 4. Adsorbent dosage effect of removal of MY on mesoporous aluminophosphate molecular sieves

Where, $\mathrm{k}$ is the rate constant, $\mathrm{Q}_{\mathrm{e}}$ and $\mathrm{Q}_{\mathrm{t}}$ are the amount of dye adsorbed per unit mass of the mesoporous $\mathrm{AlPO}_{4}$ at equilibrium and $\mathrm{t}$ is time. The plot of $\mathrm{t} / \mathrm{Q}_{\mathrm{t}}$ vs. $\mathrm{t}$ gives straight lines. Linear plots of the $t / \mathrm{Q}_{\mathrm{t}} v s$. $\mathrm{t}$ is given in the Figure 5 for $\mathrm{MY}$ adsorption on mesoporous $\mathrm{AlPO}_{4}$. The value of linear regression coefficient $\left(\mathrm{R}^{2}\right)$, very close to 1 (Table 1 ) indicates that the adsorption of $\mathrm{MY}$ on mesoporous $\mathrm{AlPO}_{4}$ is obey the pseudo-second order kinetics equation.

\section{Adsorption isotherm studies}

The distribution of MY between the adsorbent and solution was determined by Langmuir and Freundlich isotherms. 


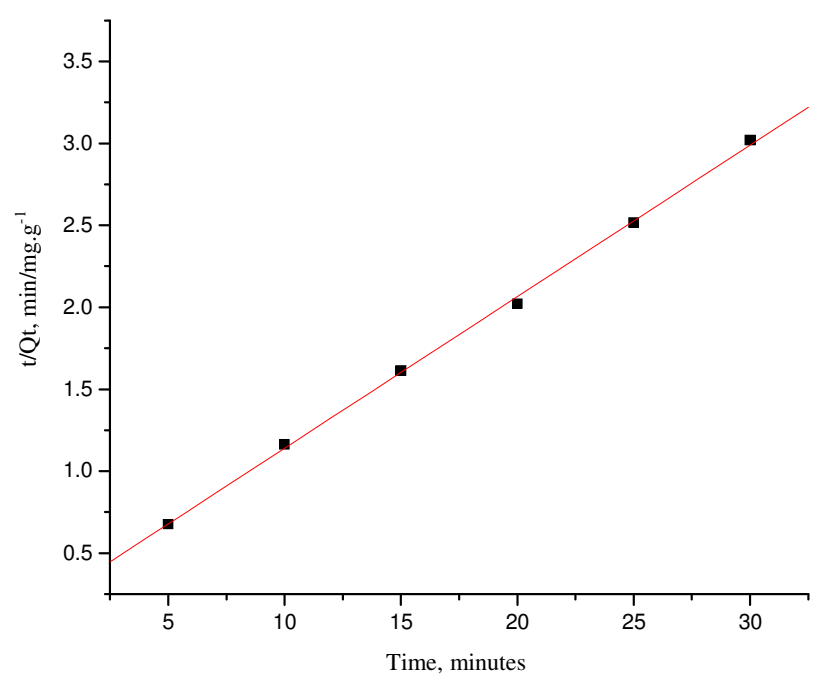

Figure 5. Pseudo second order kinetics plot

Table 1. Pseudo second order kinetic parameters

\begin{tabular}{cccc}
\hline Dye & $\mathrm{Q}_{\mathrm{e}}$ & $\mathrm{K}$ & $\mathrm{R}^{2}$ \\
\hline Metanil Yellow & 8.9893 & 0.0027 & 0.9997 \\
\hline
\end{tabular}

\section{Langmuir adsorption isotherm}

Adsorption isotherm data at different concentrations was measured for the adsorption of MY and fitted with Langmuir adsorption isotherm equation (Figure 6). This study was carried out as a model for understanding the monolayer adsorption of MY on mesoporous $\mathrm{AlPO}_{4}$. The Langmuir equation is represented as

$$
\mathrm{C}_{\mathrm{e}} / \mathrm{Q}_{\mathrm{e}}=\left(1 / \mathrm{Q}_{\max } \mathrm{K}_{\mathrm{L}}\right)+\left(\mathrm{C}_{\mathrm{e}} / \mathrm{Q}_{\max }\right)
$$

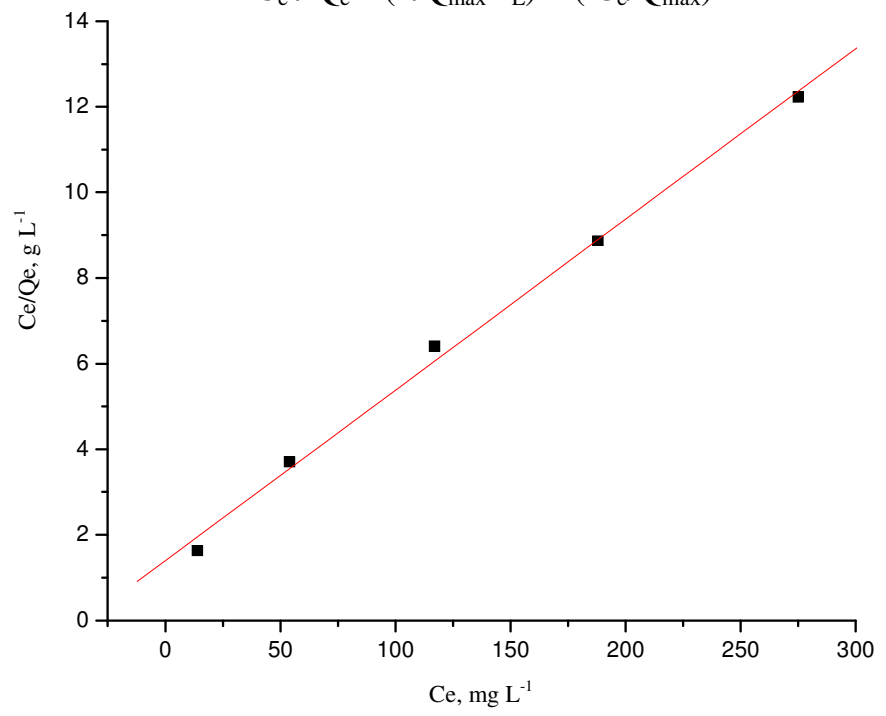

Figure 6. Langmuir adsorption isotherm plot 
Where, $Q_{e}$ is the equilibrium concentration of dyes on the adsorbent $\left(\mathrm{mg} \mathrm{g}^{-1}\right), \mathrm{C}_{\mathrm{e}}$ is the equilibrium concentration of dyes in solution $\left(\mathrm{mg} \mathrm{L}^{-1}\right), \mathrm{Q}_{\max }$ is the monolayer capacity of Adsorbent $(\mathrm{mg} / \mathrm{g})$ and $\mathrm{K}_{\mathrm{L}}$ is the Langmuir adsorption constant.

The Langmuir constant $\mathrm{K}_{\mathrm{L}}$ is a measure of the affinity between adsorbate and adsorbent and $1 / \mathrm{K}_{\mathrm{L}}$ value gives half maximum adsorption. Plot of Ce/Qe $v s . \mathrm{Ce}$ is a straight line with slope $1 / \mathrm{Q}_{\max }$ and intercept $1 / \mathrm{Q}_{\max } \mathrm{K}_{\mathrm{L}}$. The $\mathrm{R}^{2}$ values for the adsorption of $\mathrm{MY}$ on mesoporous $\mathrm{AlPO}_{4}$ is given in the Table 2 . The correlation coefficient $\left(\mathrm{R}^{2}\right)$ values are very close to 1 , indicated that the adsorption follows the Langmuir adsorption isotherm. The maximum adsorption capacity of mesoporous $\mathrm{AlPO}_{4}$ for $\mathrm{MY}$ is $75 \mathrm{mg} / \mathrm{g}$.

\section{Freundlich adsorption isotherm}

The adsorption studies were carried out at various concentrations for the adsorption of MY. The adsorption values were applied to the Freundlich equation to verify the adsorption isotherms (Table 2). This study has been carried out as a model for understanding the multilayer adsorption of MY.

Table 2. Langmuir and Freundlich adsorption isotherm parameters

\begin{tabular}{|c|c|c|c|c|c|c|c|}
\hline \multirow{2}{*}{ Dye } & \multicolumn{3}{|c|}{$\begin{array}{l}\text { Langmuir adsorption isotherm } \\
\text { parameters }\end{array}$} & \multicolumn{4}{|c|}{$\begin{array}{l}\text { Freundlich adsorption isotherm } \\
\text { parameters }\end{array}$} \\
\hline & $\begin{array}{l}\mathrm{Q}_{\max } \\
\mathrm{mg} / \mathrm{g}\end{array}$ & $\mathrm{K}_{\mathrm{L}}$ & $\mathrm{R}^{2}$ & $1 / \mathrm{n}$ & $\mathrm{n}$ & $\mathrm{K}_{\mathrm{F}}$ & $\mathrm{R}^{2}$ \\
\hline $\begin{array}{l}\text { Metanil } \\
\text { Yellow }\end{array}$ & 25.07 & 0.0283 & 0.9981 & 0.32815 & 3.05 & 3.7485 & 0.9941 \\
\hline
\end{tabular}

The Freundlich equation is represented as

$$
\ln \mathrm{Q}_{\mathrm{e}}=\ln \mathrm{K}_{\mathrm{F}}+(1 / \mathrm{n}) \ln \mathrm{C}_{\mathrm{e}}
$$

Where, $\mathrm{K}_{\mathrm{F}}$ and $1 / \mathrm{n}$ are the Freundlich constants indicate the adsorption capacity and adsorption intensity respectively. The plot of $\operatorname{lnQ}_{\mathrm{e}} v s . \operatorname{lnC}_{\mathrm{e}}$ gave a straight line (Figure 7) with the intercept $\ln \mathrm{K}_{\mathrm{F}}$ and the slope $1 / \mathrm{n}$.

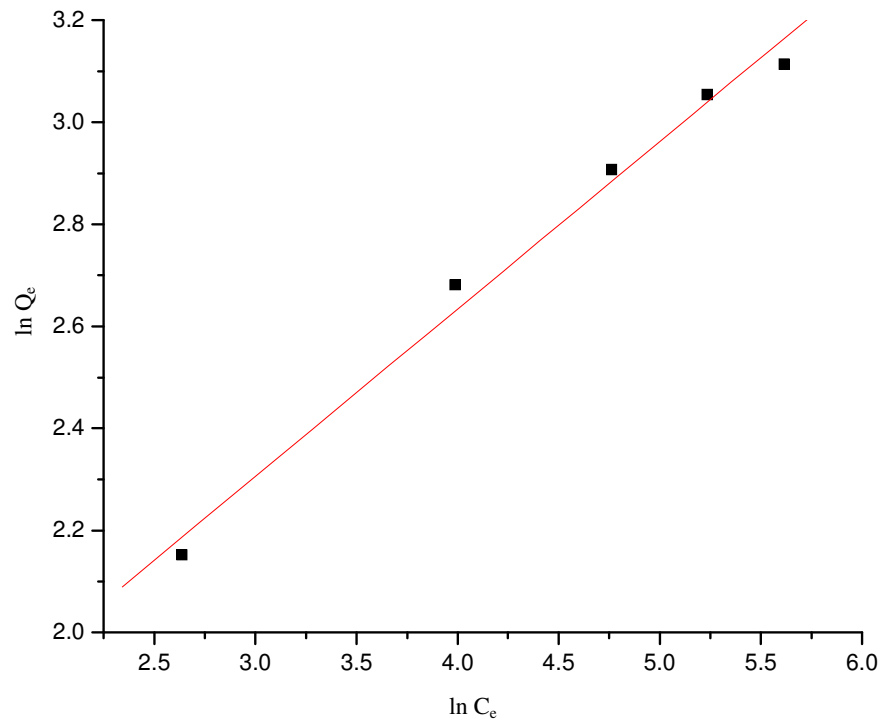

Figure 7. Freundlich adsorption isotherm plot 
The Freundlich constant, $\mathrm{n}$ should have values lying in the range of 1 to 10 for classification as favorable adsorption. In this study the value of $1 / \mathrm{n}(<1)$ obtained from the linear plot of $\ln _{\mathrm{e}} v s$. $\ln _{\mathrm{e}}$ indicates that a stronger bond present in between $\mathrm{MY}$ with mesoporous $\mathrm{AlPO}_{4}$ and also the positive ' $\mathrm{n}$ ' value indicates the process is classified as favourable adsorption.

\section{Conclusion}

Mesoporous aluminophosphate molecular sieve was successfully applied for the removal of MY from aqueous solution. The adsorption equilibrium attained at 20 minutes due to the rapid adsorption of MY on mesoporous $\mathrm{AlPO}_{4}$. The adsorption isotherm studies showed that the adsorption process was followed Langmuir adsorption isotherm.

\section{Acknowledgement}

Financial support from University Grant Commision, New Delhi (Ref: Project No. F. 36$168 / 2009$ (SR)) is gratefully acknowledged. The author Kumarasamy Muthuraja is thankful to the Manonmaniam Sundaranar University, Tirunelveli-627 012, Tamilnadu, India for the award of USRF fellowship.

\section{References}

1. Saylkan F, Asilt"urk M, Tatar P, Kiraz N, Arpac E and Sayılkan H, J Hazard Mater., 2007, 144, 140-146.

2. Rajgopal S, Karthikeyan T, Prakash Kumar B G and Miranda L R, Chem Eng J., 2006, 116(3), 211-217.

3. Daneshvar N, Khataee A R, Rasoulifard M H and Pourhassan M, J Hazard Mater., 2007, 143(1), 214-219.

4. Mckay G, Porter J F and Prasad G R, Water Air Soil Pollut., 1999, 114, 423-438.

5. Chellapandian Kannan, Thiravium Sundaram and Thayumanavan Palvannan, $J$ Hazard Mater., 2008, 157(1), 137-145.

6. Chellapandian Kannan, Kumarasamy Muthuraja and Murugan R. Devi, J Hazard Mater., 2012; DOI:10.1016/j.jhazmat.2012.11.016. 